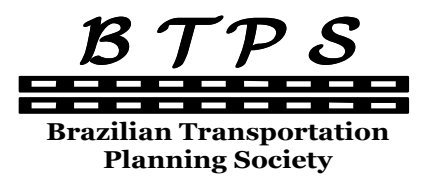

Journal of Transport Literature

Vol. 8, n. 2, pp. 7-37, Apr. 2014

Research Directory

\title{
Transportation with volume discount - a case study of a logistic operator in Ghana
}

[Transporte com desconto de volume - um estudo de caso de um operador logístico em Gana]

\author{
Abdul-Salam Sibidoo Mubashiru* \\ Kwame Nkrumah University of Science and Technology, Ghana
}

Submitted 24 Jan 2013; received in revised form 17 Apr 2013; accepted 18 Oct 2013

\begin{abstract}
Network models and integer programming are well known variety of decision making problems. A very useful and widespread area of application is the management and efficient use of scarce resources to increase productivity. These applications include operational problems such as the distributions of goods, production scheduling and machine sequencing, and planning problems such as capital budgeting facility allocation, portfolio selection, and design problems such as telecommunication and transportation network design. The transportation problem, which is one of network integer programming problems is a problem that deals with distributing any commodity from any group of 'sources' to any group of destinations or 'sinks' in the most cost effective way with a given 'supply' and 'demand' constraints. Depending on the nature of the cost function, the transportation problem can be categorized into linear and nonlinear transportation problem. We applied Karush-Kuhn-Tucker (KKT) optimality algorithm to solve our problem of transportation with volume discount for a logistic operator in Ghana.
\end{abstract}

Key words: network models, integer programming, Karush-Kuhn-Tucker, transportation.

\section{Resumo}

Os modelos de rede e programação inteira são uma variedade bem conhecida de problemas de tomada de decisão. Uma área muito útil e difundida de aplicação é o uso e gestão eficiente de recursos escassos para aumentar a produtividade. Estas aplicações incluem problemas operacionais como a distribuição de mercadorias, programação de produção e sequenciamento de máquinas e problemas de planejamento, como a alocação de orçamento de capital de instalações, seleção de portfolios, e problemas de desenho de redes de telecomunicações e transportes. O problema do transporte, que é um dos problemas da rede de programação inteira, é um problema que lida com a distribuição de qualquer bem de qualquer grupo de 'fontes' para qualquer grupo de destinos ou na forma mais efetiva em custos, dadas restrições de 'oferta' e de 'demanda'. Dependendo da natureza da função de custo, o problema do transporte pode ser categorizado em problemas de transporte linear e não linear. Neste artigo é aplicado o algoritmo de otimização Karush-Kuhn-Tucker (KKT) para resolver o problema de transportes com volume de descontos para um operador logístico em Gana.

Palavras-Chave: modelos de rede, programação inteira, Karush-Kuhn-Tucker, transportes.

*Email: sibidoo@yahoo.com.

\section{Recommended Citation}

Mubashiru, A-S. S. (2014) Transportation with volume discount - a case study of a logistic operator in Ghana. Journal of Transport Literature, vol. 8, n. 2, pp. 7-37.

- JTL/RELIT is a fully electronic, peer-reviewed, open access, international journal focused on emerging transport markets and published by BPTS - Brazilian Transport Planning Society. Website www.transport-literature.org. ISSN 2238-1031.

This paper is downloadable at www.transport-literature.org/open-access. 


\section{Introduction}

This paper seeks to solve a transportation problem with volume discount. The costs of goods are determined by factors such as: the costs of raw materials, labour, and transport. When cost of raw materials rises, so does the cost of the goods. Transportation cost also affects the pricing system. It is assumed that the cost of goods per unit shipped from a give source to a given destination is fixed regardless of the volume shipped. But in actuality the cost may not be fixed. Volume discounts are sometimes available for large shipments so that the marginal costs of shipping one unit might follow a particular pattern. Our focus will be to develop a mathematical model using optimization techniques to close the demand and supply gap by discounting so as to minimize total transportation cost.

This research seeks to apply the existing general nonlinear programming algorithms to solve our problem. The research strategy that the study will utilize is the descriptive method. In this study, primary and secondary research will be both incorporated. The reason for this is to be able to provide adequate discussion for the readers that will help them understand more about the issue and the different variables that involve with it. The primary data for the study will be represented by the survey results that will be acquired from the respondents. On the other hand, the literature reviews to be presented in the second Section of the study will represent the secondary data of the study. The secondary sources of data will come from published articles from books, journals, theses and related literature. Different algorithms to the various transportation problems will be presented.

Until recently, heavy trucks could load up to any capacity without limit. These trucks normally exceed the average loading capacity of the truck. This was partially due to high transportation cost. Drivers and transport owners together with transport users had to find a way of compensating for the high cost of transport by increasing the truck load so as to maximize profit. This had ripple effect on the state as a whole: increase road accidents, destruction of roads, pressure is also put on the vehicle, and longer time being spent on the road before getting destination. There is also the effect of increased cost of goods thereby increasing inflation. This has driven the attention of the stakeholders to find a lasting solution 
to the problems. There is therefore the need to determine the maximum loading capacity of trucks.

The purpose of this work is to find out whether given volume discounts on transportation costs could minimize total transportation cost thereby increasing total revenue of producers and retailers as well as solving some of the aforementioned problems associated with transportation.

This paper is organized in the following way. In Section 1, we presented a background study of transportation problem, objectives, methodology, justification and limitations of the study. In Section 2, related works in the field of transportation problems will be discussed. Section 3 presents various existing algorithms for solving the various transportation problems. Section 4 presents data collection and analysis of the study. And finally, we present the conclusions and recommendations of the study.

\section{Background}

Contemporary research in logistics management relies on an increased recognition that an integrated plan requires coordinating different functional specialties within a system in keeping with this trend; we focus on the integration of production, inventory and transportation arising in a supplier- retailer logistic system. In the general inventory models, costs of such issues are usually accounted according to the following assumptions: the production cost is proportional to the quantity of products produced. The ordering cost, which refers to the charge for preparing of production, is independent of the quantity ordered. The inventory cost (shortage cost) is proportional to the quantity of products stored (out of order) as well as the duration for which these items are stored (stock out). When products are delivered from the supplier to the consumer, transportation costs are incurred. In the traditional economic order quantity (EOQ) model, the transportation cost is calculated together with the production cost, or with the ordering cost. However, in a practical logistic system, the transportation cost of a vehicle includes both of the fixed cost and the variable cost. The fixed cost, which is considered to be a constant sum in each period, refers to some necessary expenses such as parking fare and rewards to the driver. As to the variable cost, it depends mainly on the oil consumed, which is related directly to the distance travelled. In 
short, considering the real condition, it is unreasonable to assume that the transportation cost is proportional to the quantity delivered or is a constant sum.

Transportation models provide a powerful framework to meet this challenge. They ensure the efficient movement and timely availability of raw materials and finished goods. Transportation problem is a linear programming problem stemmed from a network structure consisting of a finite number of nodes and arcs attached to them. When the transportation plan is made up, the volume discounts brought by large quantities of transportation should not be pursuited excessively. As this would bound to increase inventory costs throughout the system, also when the inventory strategy is determined, transportation costs cannot be dealt with as a fixed fee, but as a variable cost directly impacting on transportation frequency and inventory distribution. Under the prerequisite of comprehensively balancing the transportation costs and inventory costs, the objectives that Inventory-Transportation Integrated Optimization problem (ITIO) are to optimize the logistics system, reduce logistics costs, and determine the transportation program and inventory strategy of the system.

One of the earliest and most fruitful applications of linear programming techniques has been the formulation and solution of the transportation problems as a linear programming problem. The basic transportation problem was originally developed by Hitchcock (1941). The objective of the transportation problem is to determine the optimal amounts of a commodity to be transported from various supply points to various demand points so that the total transportation cost is a minimum. The unit costs i.e. the cost of transporting one unit from a particular supply point to a particular demand point, the amounts available at the supply points and the amounts required at the demand points are the parameters of the transportation problem.

Industrial development today depends on the efficiency of the transportation and logistics activities. Transportation can be described as a flow of materials between two organizations. The first formulation and discussion of a planar transportation model was introduced by Hitchcock (1941). The objective was to find the way of transporting homogeneous product from several sources to several destinations so that the total cost can be minimized. The Transportation Problem (TP) is well known as one of the practical network problems and there are many investigations of evolutionary approaches to solve the varieties of transportation problem. In the real-life applications, it is often that the problems to be solved 
have a large-scale and has to satisfy several other additional constraints. For example, Sun (1998) introduced the transportation problem with exclusionary side constraint. To solve this problem, he developed a Tabu search procedure.

Network models and integer programs are well known variety of decision problems. A very useful and widespread area of application is the management and efficient use of scarce resources to increase productivity. These applications include operational problems such as the distributions of goods, production scheduling and machine sequencing, and planning problems such as capital budgeting facility allocation, portfolio selection, and design problems such as telecommunication and transportation network design. The transportation problem which is one of the network integer programming problems is a problem that deals with distributing any commodity from any group of sources to any group of destinations or sinks in the most cost effective way with a given supply and demand constraints.

Depending on the nature of the cost function, the transportation problem can be categorized into linear and nonlinear transportation problem. In the linear transportation problem (ordinary transportation problem) the cost per unit commodity shipped from a given source to a given destination is constant, regardless of the amount shipped. Also it is always supposed that the mileage (distance) from every source to every destination is fixed. To solve such transportation problem we have the streamlined simplex algorithm which is very efficient. However, in actuality we can see at least two cases that the transportation problem fails to be linear. First, the cost per unit commodity transported may not be fixed for volume discounts sometimes are available for large shipments. This would make the cost function either piecewise linear or just separable concave function. In this case the problem may be formulated as piecewise linear or concave programming problem with linear constraints. In special conditions such as transporting emergency materials when natural calamity occurs or transporting military supplies during war time, where carrying network may be destroyed, mileage from some sources to some destinations are no longer definite. So the choice of different measures of distance leads to nonlinear (quadratic, convex, concave...) objective function. In the above cases, solving the transportation problem is not as simple as that of the linear one. 
In our work, solution procedures to the generalized transportation problem taking nonlinear cost function as a result of volume discounts are investigated. In particular, the nonlinear transportation problem considered in this research is stated as follows; we are given a set of $n$ sources of commodity with known supply capacity and a set of $m$ destinations with known demands. The function of transportation cost, nonlinear, and differentiable for a unit of product from each source to each destination. We are required to find the amount of product to be supplied from each source (may be market) to meet the demand of each destination in such a way as to minimize the total transportation cost.

\section{Models of transportation volume with discounts}

It is known to be real that the per unit transportation cost from a specific supply source to a given demand sink is dependent on the quantity shipped, so that there exist finite intervals for quantities where price breaks are offered to customers. Thus, such a quantity discount results in a non-convex, piecewise linear functional. Balachandran and Perry (2006) presented a model with an algorithm to solve this problem. This algorithm, with minor modifications, is shown to encompass the "incremental" quantity discount and the "fixed charge" transportation problems as well. It is based upon a branch-and-bound solution procedure. The branches lead to ordinary transportation problems, the results of which are obtained by utilizing the "cost operator" for one branch and "rim operator" for another branch. Suitable illustrations and extensions were also provided.

Goossens et al. (2007) studied the procurement problem faced by a buyer who needs to purchase a variety of goods from suppliers applying a so-called total quantity discount policy. This policy implies that every supplier announces a number of volume intervals and that the volume interval in which the total amount ordered lies determines the discount. Moreover, the discounted prices apply to all goods bought from the supplier, not only to those goods exceeding the volume threshold. The author's referred to this cost-minimization problem as the TQD problem. The authors give a mathematical formulation for this problem and argue that not only it is NP-hard, but also that there exists no polynomial-time approximation algorithm with a constant ratio (unless $\mathrm{P}=\mathrm{NP}$ ). Apart from the basic form of the TQD problem, the authors described three variants. In a first variant, the market share that one or more suppliers can obtain is constrained. Another variant allows the buyer to procure more 
goods than strictly needed, in order to reach a lower total cost. In a third variant, the number of winning suppliers is limited. The authors showed that the TQD problem and its variants can be solved by solving a series of min-cost flow problems. Finally, they investigated the performance of three exact algorithms (min-cost flow based branch-and-bound, linear programming based branch-and-bound, and branch-and-cut) on randomly generated instances involving fifty (50) suppliers and hundred (100) goods. It turns out that even the large instances of the basic problem are solved to optimality within a limited amount of time. However, the authors found that different algorithms perform best in terms of computation time for different variants.

Discount in transportation cost on the basis of transported amount is extended to a solid transportation problem. In a transportation model, the available discount is normally offered on items/criteria, etc., in the form AUD (all unit discounts) or IQD (incremental quantity discount) or combination of these two. Ojha et al. (2010) considered a transportation model with fixed charges and vehicle costs where AUD, IQD or combination of AUD and IQD on the price depending upon the amount is offered and varies on the choice of origin, destination and conveyance. To solve the problem, Genetic Algorithm (GA) based on Roulette wheel selection, arithmetic crossover and uniform mutation has been suitably developed and applied. To illustrate the models, numerical examples have been presented. Here, different types of constraints are introduced and the corresponding results are obtained. To have better customer service, the entropy function is considered and it is displayed by a numerical example. To exhibit the efficiency of GA, another method-weighted average method for multi-objective is presented, executed on a multi-objective problem and the results of these two methods are compared.

Crama et al. (2004) described the purchasing decisions faced by a multi-plant company. The suppliers of this company offer complex discount schedules based on the total quantity (rather than cost) of ingredients purchased. The schedules simultaneously account both for corporate purchases and for purchases at the individual plant level. The complexity of the purchasing decisions is further increased due to the existence of alternative production recipes for each final product. We formulate the corresponding cost-minimization problem as a nonlinear mixed 0-1 programming problem. We propose various ways to linearize this. 


\section{Methodology}

In most transportation problem cases it was assumed that the cost per unit shipped from a given source to a given destination is fixed, regardless of the amount shipped. In actuality, this cost may not be fixed. Volume discounts sometimes are available for large shipments, so that the marginal cost of shipping one more unit might follow a nonlinear pattern. The resulting cost of shipping $x$ units then is given by a nonlinear function $C(x)$, which is a piecewise linear function with slope equal to the marginal cost. Consequently, if each combination of source and destination has a similar shipping cost function, so that the cost of shipping $x_{i j}$ units from source $i(i=1,2, \ldots m)$ to destination $j(j=1,2, \ldots n)$ is given by a nonlinear function $C_{i j}\left(x_{i j}\right)$, then the overall objective function to be minimized is $f(x)=$ $C_{i j}\left(x_{i j}\right)$

Even with this nonlinear objective function, the constraints normally are still the special linear constraints that fit the general transportation problem model. In this section we shall provide an in depth explanation of the solution procedures to the generalized transportation problem taking nonlinear cost function. In particular, the nonlinear transportation problem considered in this paper as a result of volume discount on shipping cost is stated as follows; we are given: (i) a set of $\mathrm{n}$ sources of commodity with known supply capacity and a set of $\mathrm{m}$ destinations with known demands, (ii) the function of transportation cost, nonlinear, and differentiable for a unit of product from each source to each destination. We are required to find the amount of product to be supplied from each source to meet the demand of each destination in such a way as to minimize the total transportation cost.

Our approach to solve this problem is applying the existing general nonlinear programming algorithms to it making suitable modifications in order to use the special structure of the problem. In order to understand our approach, it is necessary to have a good understanding of some of the background polyhedral theory for both the general linear and nonlinear programming problems. The general transportation problem is modelled as: 
Minimize $\mathrm{Z}=\sum_{i, j} C_{i j} X_{i j}$

Subject to the constraints

$$
\begin{gathered}
\sum_{j=1}^{n} X_{i j}=S_{i} i=1,2, \ldots, ., m \\
\sum_{i=1}^{m} X_{i j}=D_{j} \quad j=1,2, \quad ., \quad ., n \\
X_{i j} \geq 0
\end{gathered}
$$

\subsection{Polyhedral Sets}

A set $P$ in an $n$ dimensional normed vector space $E^{n}$ is called polyhedral set if it is the intersection of a finite number of closed-half spaces, i.e. $P=\left\{X: P_{i}^{t} X \leq \alpha_{i}, i=1, \ldots, m\right\}$, where $P_{i}$ is a non zero vector in $\mathrm{E}^{\mathrm{n}}$ and $\alpha_{\mathrm{i}}$ is a scalar. A polyhedral set is a closed convex set and can be represented by a finite number of inequalities and/or equations. We consider the polyhedral set $=\{x: A x=b, x \geq 0\}$, where $\mathrm{A}$ is an $\mathrm{m} \mathrm{x} \mathrm{n}$ matrix and $\mathrm{b}$ is an $\mathrm{m}$-vector, assume also that the rank of $\mathrm{A}$ is $\mathrm{m}$. If not, assuming that $A x=b$ is consistent, we can leave aside any redundant equations. Let $P$ be non empty convex set in $E^{n}$. A vector $x \in P$ is called an extreme point of $P$ if $x=\beta x_{1}+(1-\beta) x_{2}$ with $x_{1}$ and $x_{2}$ elements of $\mathrm{P}$ and $\beta \in(0,1)$. The following are basic theorems concerning extreme points ${ }^{1}$.

Theorem 3.1.1 Let $P=\{x: A x=b, x \geq 0\}$, where $A$ is $m x n$ matrix of rank $m$, and $b$ is an $m$ vector. A point $\mathrm{x}$ is an extreme point of $\mathrm{P}$ if and only if a can be decomposed into [B, N] such that

$$
\mathrm{X}=\left(\begin{array}{c}
x B \\
x N
\end{array}\right)=\left(\begin{array}{c}
B-1 b \\
0
\end{array}\right)
$$

Where $B$ is an $m x n$ invertible matrix satisfying $B^{-1} b \geq 0$. Any such solution is called a basic feasible solution for (BFS) P. The number of extreme points of $\mathrm{P}$ is finite.

Theorem 3.1.2 (Existence of extreme points) Let $P=\{x: A x=b, x \geq 0\}$ be non empty; where $A$ is an $m x n$ matrix of rank $m$ and $b$ is an $m$ vector. Then $P$ has at least one extreme point.

\footnotetext{
${ }^{1}$ Interested readers can contact the author for proofs of these theoretical results.
} 


\subsection{Extreme Direction}

Let $\mathrm{P}$ be a non empty polyhedral set in $\mathrm{E}^{\mathrm{n}}$. A none zero vector $\mathrm{d}$ in $\mathrm{E}^{\mathrm{n}}$ is called direction or recession direction of $\mathrm{P}$ if $\mathrm{x}+\beta \mathrm{d} \in \mathrm{P}$ for each $\mathrm{x} \in \mathrm{P}$ for all $\beta \geq 0$. It follows that, $\mathrm{d}$ is a direction of $\mathrm{P}$ if and only if $\mathrm{Ad}=0$ and $\mathrm{d} \geq 0$.

Theorem 3.1.3 (Characterization of Extreme Directions) Let $P=\{x: A x=b, x \geq 0\} \neq \emptyset$, where $\mathrm{A}$ is an $\mathrm{m} \times \mathrm{n}$ matrix of rank $\mathrm{m}$, and $\mathrm{b}$ is an $\mathrm{m}$ vector. A vector $\bar{d}$ is an extreme direction of $\mathrm{P}$ if and only if $\mathrm{A}$ can be decomposed into $[\mathrm{B}, \mathrm{N}]$ such that $\mathrm{B}^{-1} \mathrm{a}_{\mathrm{j}} \leq 0$ for some column $\mathrm{a}_{\mathrm{j}}$ of $\mathrm{N}$, and $\bar{d}$ is a positive multiple of $\mathrm{d}=\left(\begin{array}{c}B-1 a j \\ e j\end{array}\right)$, where $\mathrm{e}_{\mathrm{j}}$ is an $\mathrm{n}-\mathrm{m}$ vector of zero except for in position $\mathrm{j}$ which is 1 .

Theorem 3.1.4 (Representation theorem) Let $P=\{x: A x=b, x \geq 0\} \neq \emptyset$. Let $x_{1}$, ., $x_{k}$ be the extreme points of $P$ and $d_{1}, d_{2}, . ., d_{1}$ be the extreme direction of $P$. Then $x \in P$ if and only if $x$ can be written as:

$$
\begin{aligned}
& \mathrm{x}=\sum_{j=1}^{k} \beta j \mathrm{x}_{\mathrm{j}}+\sum_{i=1}^{l} \gamma i \mathrm{~d}_{\mathrm{i}} \\
& \sum_{j=1}^{k} \beta j=1 \\
& \beta_{\mathrm{j}} \geq 0, \text { and } \gamma_{\mathrm{i}} \geq 0 .
\end{aligned}
$$

Theorem 3.1.5 (Existence of extreme directions) $P=\{x: A x=b, x \geq 0\}$ where $A$ is an $m x n$ matrix with rank $\mathrm{m}$. Then, $\mathrm{P}$ has at least one extreme direction if and only if it is unbounded.

\subsection{The Karush-Kuhn-Tucker (KKT) optimality condition for nonlinear programming problem (NPP)}

Given the nonlinear programming problem:

$$
\begin{array}{ll} 
& (\mathrm{NPP}) \min f(x) \\
\text { s.t. } & g_{i}(x) \leq 0 \quad i=1,2, \ldots, k \\
& h_{i}(x)=0 \quad j=1,2, \ldots, l
\end{array}
$$




\subsubsection{KKT Necessary optimality conditions}

Theorem Given the objective function $f: R^{n} \rightarrow R$ and the constraint functions are $g_{i}: R^{n} \rightarrow R$ and hj: $\mathrm{R}^{\mathrm{n}} \rightarrow \mathrm{R}$ and $\mathrm{I}=\left\{\mathrm{i}: \mathrm{g}_{\mathrm{i}}\left(\mathrm{x}^{*}\right)=0\right\}$. In addition, suppose they are continuously differentiable at a feasible point $\mathrm{x}^{*}$ and $\nabla \mathrm{g}_{\mathrm{i}}\left(\mathrm{x}^{*}\right)$ for $\mathrm{i} \in \mathrm{I}$ and $\nabla \mathrm{h}_{\mathrm{j}}\left(\mathrm{x}^{*}\right)$ for $\mathrm{j}=1, \ldots, \mathrm{l}$ be linearly independent. If $x^{*}$ is minimizer of the problem (NPP), then there exist scalars $\bar{\beta}_{\mathrm{i}} \mathrm{i}=1, \ldots, \mathrm{k}$ and $\bar{\gamma}_{\mathrm{j}} \mathrm{j}=1, ., ., 1$, called Lagrange multiplier, such that

$$
\begin{gathered}
\nabla \mathrm{f}\left(\mathrm{x}^{*}\right)+\sum_{j=1}^{k} \beta j \nabla \mathrm{g}_{\mathrm{i}}\left(\mathrm{x}^{*}\right)+\sum_{i=1}^{l} \gamma_{\mathrm{i}} \nabla \mathrm{h}_{\mathrm{i}}\left(\mathrm{x}^{*}\right)=0 \\
\bar{\beta}_{\mathrm{j}} \mathrm{g}_{\mathrm{j}}\left(\mathrm{x}^{*}\right)=0, \bar{\beta} \mathrm{j} \geq 0, \text { and } \bar{\gamma}_{\mathrm{j}} \in \mathrm{R}
\end{gathered}
$$

\subsubsection{KKT Necessary optimality conditions for convex NPP}

Further, if $f$ and $g_{i}$ are convex, each $h_{j}$ as affine, then the above necessary optimality conditions will also be sufficient.

\subsection{The Linear Transportation Problem}

The linear transportation problem is concerned with distributing any commodity from any group of supply centres, called sources, to any group of receiving centres, called destinations in such a way as to minimize the total distribution cost, where the cost per commodity is constant regardless of the amount transported. By letting $\mathrm{z}$ to be the total distribution cost and $x_{i j}$ the number of units to be distributed from source $i\left(s_{i}\right)$ to destination $j\left(d_{j}\right)$ the linear programming formulation of this problem become:

$$
\begin{aligned}
& \min \mathrm{z}=\sum_{i=1}^{n} \sum_{j=1}^{m} c_{i j} x_{i j} \\
& \text { s. t } \quad \sum_{j=1}^{m} x_{i j}=s_{i} \quad \text { for } \mathrm{i}=1,2, \ldots \mathrm{n} \\
& \sum_{i=1}^{n} x_{i j}=d_{j} \text { for } \mathrm{j}=1,2, \ldots \mathrm{m} \\
& \qquad x_{i j} \geq 0 \quad \forall i, j
\end{aligned}
$$

\subsection{Methods for Finding Initial Basic Feasible Solutions}

The first phase of the solving a transportation problem for optimal solution involves finding the initial basic feasible solution. An initial feasible solution is a set of arc flows that satisfies 
each demand requirement without supplying more from any origin node than the supply available. Heuristic, a common - sense procedure for quickly finding a solution to a problem is a producer most employed to find an initial feasible solution to a transportation problem. This project examines three of the more popular heuristics for developing an initial solution to transportation problem: i. The Northwest Corner Method, ii. The Least Cost Method and iii. The Vogel's Approximation Method.

The Northwest Corner Method is the simplest of the three methods used to develop an initial basic feasible solution. This notwithstanding, it is the least likely to give a good "low cost" initial solution because it ignores the relative magnitude of the costs $c_{i j}$ in making allocations. The Least-Cost Method tries to reflect the objective of cost minimization by systematically allocating to cells according to the magnitude of their unit costs. Finally, the Vogel's Approximation Method (VAM) is by far the best method (better than the Northwest Corner Method and the Last-Cost Method) of developing an initial basic feasible solution to transportation problems. In many cases the initial solution obtained by the VAM will be optimal. It consists of making allocations in a manner that will minimize the penalty (regret or opportunity cost) for selecting the wrong cell for an allocation.

\subsection{Optimality-Test Algorithm for Transportation Problems}

These are methods of determining the optimal solutions for transportation problems following the determination of the initial basic feasible solution: i. the Stepping Stone Method and ii. The Modified Distribution Method shall be the focus of this project.

The Stepping Stone optimality test begins, once an initial basic feasible solution is obtained for the transportation problem, by determining if the total transportation cost can be further reduced by entering a nonbasic variable (i.e. allocating units to an empty cell) into the solution. Thus each empty cell is evaluated to determine if the cost of shifting a unit to that cell from a cell containing a positive unit will decrease. A closed loop of occupied cells is used to evaluate each nonbasic valuable. An initial basic feasible solution is considered optimal if the total transportation cost cannot be lowered/ decreased by reallocating units between cells. The Modified Distribution Method of solution is a variation of the Stepping Stone method based on the dual formulation. The difference between the two is that with the MODI, unlike the stepping-stone method, it is not necessary to determine all closed paths for 
nonbasic variable. The $\mathrm{C}_{\mathrm{ij}}{ }_{\mathrm{ij}}$ values are instead determined simultaneously and the closed path is identified only for the entering nonbasic variable. In the MODI method, a value $u_{i}$ is defined for each row (i) and a value $v_{j}$ is defined for each column (j) in the transportation tableau.

\subsection{Solution procedures to nonlinear transportation Problems (NTP)}

This section considers the solution to the transportation problem with nonlinear cost function arising from volume discount. We shall consider different solution procedures depending on the nature of the objective cost function. Before considering the different special cases, let us first formulate the KKT condition and general algorithm for the problem. Given a differentiable function $\mathrm{C}: \mathrm{R}^{\mathrm{nm}} \rightarrow \mathrm{R}$. We consider a nonlinear transportation problem (NTP),

$$
\begin{aligned}
& \text { Min } C(x) \\
& \text { s.t } A x=b, \quad x \geq 0
\end{aligned}
$$

\subsubsection{The KKT Optimality Condition for the NTP}

Given the transportation table as below:

\begin{tabular}{|cccccc|}
\hline$\frac{\partial C(\bar{x})}{\partial X 11}$ & $\cdots$ & $\cdots$ & $\frac{\partial C(\bar{x})}{\partial X 1 \mathrm{~m}}$ & $\mathrm{~S}_{1}$ & $\mathrm{U}_{1}$ \\
\hline$\ldots$ & $\ldots$ & $\ldots$ & $\ldots$ & $\ldots$ & $\cdots$ \\
\hline$\ldots$ & $\frac{\partial C(\bar{x})}{\partial X \mathrm{ij}}$ & $\cdots$ & $\cdots$ & $\mathrm{S}_{\mathrm{i}}$ & $\mathrm{U}_{\mathrm{i}}$ \\
\hline$\frac{\partial C(\bar{x})}{\partial X \mathrm{n} 1}$ & $\cdots$ & $\cdots$ & $\frac{\partial C(\bar{x})}{\partial X \mathrm{~nm}}$ & $\mathrm{~S}_{\mathrm{n}}$ & $\mathrm{U}_{\mathrm{n}}$ \\
\hline $\mathrm{d}_{1}$ & $\cdots$ & $\cdots$ & $\mathrm{d}_{\mathrm{m}}$ & & \\
\hline $\mathrm{v}_{1}$ & $\ldots$ & $\ldots$ & $\mathrm{V}_{\mathrm{m}}$ & & \\
\hline
\end{tabular}

Where $\bar{x}$ is the current basic solution. The Lagrange function for the NTP is formulated as $\mathrm{z}(\mathrm{x}, \beta, \mathrm{w})=\mathrm{C}(\mathrm{x})+\mathrm{w}(\mathrm{b}-\mathrm{Ax})-\beta \mathrm{x}$. Where $\beta$ and $\mathrm{w}$ are Lagrange multipliers and $\beta \in \mathrm{R}^{\mathrm{nm}}$. The optimal point $\bar{x}$ should satisfy the KKT conditions:

$$
\begin{gathered}
\nabla \mathrm{z}=\nabla \mathrm{C}(\bar{x})-\mathrm{w}^{\mathrm{T}} \mathrm{A}-\beta=0 \\
\beta \bar{x}=0 \\
\beta \geq 0 \\
\bar{x} \geq 0
\end{gathered}
$$


Specifically for each cell $(i, j)$ we have

$$
\begin{gathered}
\frac{\partial z}{\partial X \mathrm{ij}}=\frac{\partial C(\bar{x})}{\partial X \mathrm{ij}}-(\mathrm{u}, \mathrm{v})\left(\mathrm{e}_{\mathrm{i}}, \mathrm{e}_{\mathrm{n}+\mathrm{j}}\right)-\beta_{\mathrm{ij}}=0 \\
\beta_{\mathrm{ij}} \mathrm{x}_{\mathrm{ij}}=0 \\
\mathrm{x}_{\mathrm{ij}} \geq 0 \\
\beta_{\mathrm{ij}} \geq 0
\end{gathered}
$$

where $\mathrm{k}=1 \ldots \mathrm{mn}$ and $\mathrm{w}=(\mathrm{u}, \mathrm{v})=\left(\mathrm{u}_{1}, \mathrm{u}_{2}, \ldots, \mathrm{u}_{\mathrm{n}}, \mathrm{v}_{1}, \mathrm{v}_{2}, \ldots, \mathrm{v}_{\mathrm{m}}\right), \mathrm{e}_{\mathrm{k}} \in \mathrm{R}^{\mathrm{m}+\mathrm{n}}$ is a vector of zeros except at position $\mathrm{k}$ which is 1 . From the conditions (3.1) and $\beta k \geq 0$, we get,

$$
\begin{gathered}
\frac{\partial z}{\partial X \mathrm{ij}}=\frac{\partial C(\bar{x})}{\partial X \mathrm{ij}}-\left(\mathrm{u}_{\mathrm{i}}+\mathrm{v}_{\mathrm{j}}\right) \geq 0 \\
\mathrm{x}_{\mathrm{ij}} \frac{\partial z}{\partial X \mathrm{ij}}=\mathrm{x}_{\mathrm{ij}} \frac{\partial C(\bar{x})}{\partial X \mathrm{ij}}-\left(\mathrm{u}_{\mathrm{i}}+\mathrm{v}_{\mathrm{j}}\right)=0 \\
\mathrm{x}_{\mathrm{ij}} \geq 0
\end{gathered}
$$

\subsubsection{General Solution Procedure for the NTP}

- Initialization: Find an initial basic feasible solution $\bar{x}$

- Iteration:

- Step 1) If $\bar{x}$ is KKT point, stop. Otherwise go to the next step;

- Step 2) Find the new feasible solution that improves the cost function and go to Step 1.

\subsection{Transportation Problem with Concave Cost Functions}

For large shipments, volume discount may be available sometimes. In this case the cost function of the transportation problem generally takes concave structure for it is separable and the marginal cost (cost per unit commodity shipped) decreases with increase of the amount of shipment; and increasing, because of the total cost increase per addition of unit commodity shipped. The discount (1) may be either directly related to the unit commodity: (2) or have the same rate for some amount. 
Case 1: If the discount is directly related to the unit commodity the resulting cost function will be continues and have continues first order partial derivatives. The graph of $C_{i j}\left(x_{i j}\right)$ will look like:

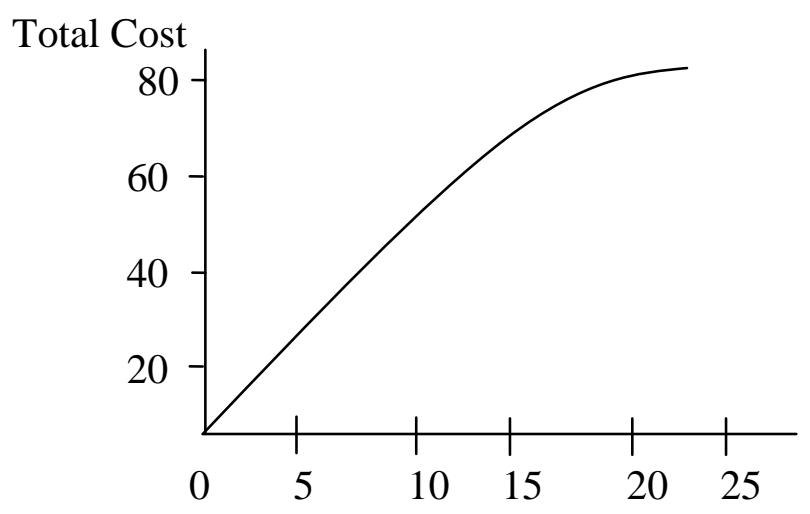

Nonlinear programming formulation of such a problem is given by

$$
\begin{aligned}
& \text { Minimize } \mathrm{Z}=\sum_{i, j} C_{i j} X_{i j} \\
& \text { Subject to the constraints } \\
& \sum_{j=1}^{n} X_{i j}=\mathrm{S}_{\mathrm{i}} \quad \mathrm{I}=1,2, ., ., \mathrm{m} \\
& \sum_{i=1}^{m} X_{i j}=\mathrm{D}_{\mathrm{j}} \quad \mathrm{j}=1,2, ., ., \mathrm{n} \\
& \mathrm{X}_{\mathrm{ij}} \geq 0
\end{aligned}
$$

Where $\mathrm{C}_{\mathrm{ij}}: \mathrm{R} \rightarrow \mathrm{R}$. Now before we go to look for an optimal solution let us state an important theorem:

Theorem 3.3.1.2 Let $\mathrm{f}$ be concave and continues function and $\mathrm{P}$ be a non empty compact polyhedral set. The optimal solution to the problem $\min \mathrm{f}(\mathrm{x}), \mathrm{x} \in \mathrm{P}$ exists and can be found at an extreme point of $\mathrm{P}^{2}$.

Because of the above theorem, it suffice to consider only the extreme points to find the minimum; the following is the procedure. After we find the initial basic feasible solution (which are $n+m-1$ in number), let $\bar{x}$ be the basic solution we have in the current iteration.

\footnotetext{
${ }^{2}$ Interested readers can contact the author for proofs of these theoretical results.
} 
Next let us decompose our $\bar{x}$ to $\left(\bar{x}_{\mathrm{B}}, \bar{x}_{\mathrm{N}}\right)$ where $\bar{x}_{\mathrm{B}}$ and $\mathrm{x}_{\mathrm{N}}$ are the basic and nonbasic variables respectively. Since $\bar{x}_{\mathrm{B}}>0$, the complementary slackness condition given in equation (3.3) above gives as $\mathrm{m}+\mathrm{n}-1$ equations;

$$
\frac{\partial z}{\partial X B \mathrm{ij}}=\frac{\partial C(\bar{x})}{\partial X B \mathrm{ij}}-\left(\mathrm{u}_{\mathrm{i}}+\mathrm{v}_{\mathrm{j}}\right)=0
$$

From the above relation we can determine the values of $u_{i}$ and $v_{j}$ by assigning one of $u_{i}{ }_{i} s$ the value zero for we have $m+n$ variables, $u_{i}$ and $v_{j}$. Then we calculate $\frac{\partial z}{\partial X i j}$ for the non basic variable $\mathrm{x}_{\mathrm{ij}}$. Since all $\mathrm{x}_{\mathrm{ij}}$ are zero at the extreme, the complementary slackness condition is satisfied. Therefore if equation (3.2) is satisfied for all no basic variables $\mathrm{x}_{\mathrm{ij}}, \bar{x}$ is a KKT point. Otherwise, if $\frac{\partial z}{\partial X i j}-\left(u_{i}+v_{j}\right)<0$, We shall move to look for better basic solution such that all the constraints (feasibility conditions) are satisfied. We do this by using the same procedure as the transportation simplex algorithm as stated below.

\subsubsection{The Transportation Concave Simplex Algorithm (TCSA)}

- Initialization: Find the initial basic feasible solution using some rule like the north west corner rule.

- Iteration:

- Step 1) determine the values of $\mathrm{u}_{\mathrm{i}}$ and $\mathrm{v}_{\mathrm{j}}$ from the equation, $\frac{\partial C(\bar{x})}{\partial X B \mathrm{ij}}-\left(\mathrm{u}_{\mathrm{i}}+\mathrm{v}_{\mathrm{j}}\right)=0$, where $\mathrm{x}_{\mathrm{Bij}}$ are the basic variables;

- Step 2) If $\frac{\partial C(\bar{x})}{\partial X B \mathrm{ij}}-\left(\mathrm{u}_{\mathrm{i}}+\mathrm{v}_{\mathrm{j}}\right) \geq 0$, for all $\mathrm{x}_{\mathrm{ij}}$ non basic, stop, $\bar{x}$ is KKT point. Otherwise go to Step 3;

- Step 3) Calculate $\frac{\partial z}{\partial X r l}=\min \left\{\frac{\partial C(\bar{x})}{\partial X \mathrm{ij}}-\left(\mathrm{u}_{\mathrm{i}}+\mathrm{v}_{\mathrm{j}}\right)\right\} \mathrm{x}_{\mathrm{rl}}$ will enter the basis. Allocate $\mathrm{x}_{\mathrm{rl}}=\theta$ where $\theta$ is found as in the linear transportation case. Adjust the allocation so that the constraints are satisfied. Determine the leaving variable say $\mathrm{x}_{\mathrm{Brk}}$, where $\mathrm{x}_{\mathrm{Brk}}$ is the basic variable comes to zero first while making the adjustment. Then find the new basic variable and go to Step 1. 
The feasible set of our problem is a non empty polyhedral set. And by definition, a polyhedral set $\mathrm{P}$ is a set bounded with a finite number of hyperplanes from which it follows that it possesses finite number of extreme points. In each step of the algorithm, we jump from one extreme point to another looking for a better feasible solution implying that the algorithm will terminate after a finite iteration. In addition since for all $\mathrm{i}$ and $\mathrm{j}, 0 \leq x i j \leq \max \left\{\mathrm{s}_{\mathrm{i}}, \mathrm{d}_{\mathrm{j}}\right\}, \mathrm{P}$ is bounded that guarantees the existence of minimum value.

Case 2: In the case when the volume discount is fixed for some amount of commodity, rather than varying with unit amount shipped, the transportation cost function will be piecewise linear concave yet increasing. The graph is like:

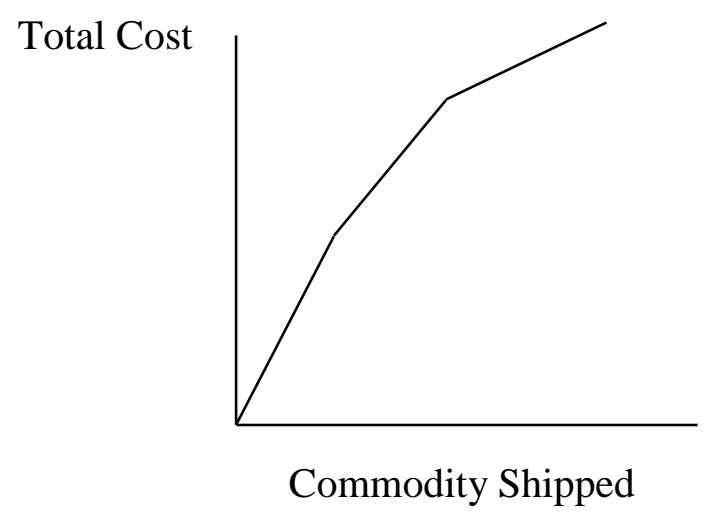

Figure 3.2: Transportation problem with piecewise linear concave cost

To avoid complication, assuming that to each combination of source and destination, the interval in which the marginal cost (cost per unit commodity) changes is the same, the cost of shipping $\mathrm{x}_{\mathrm{ij}}$ units from source $i$ to destination $j$ is given by $\mathrm{C}_{\mathrm{ij}}\left(\mathrm{x}_{\mathrm{ij}}\right)$, then the nonlinear programming formulation of the problem is given by

$$
\text { Minimize } \mathrm{Z}=\sum_{i, j} C i j X i j
$$

Subject to the constraints

$$
\begin{array}{ll}
\sum_{j=1}^{n} X i j=\mathrm{S}_{\mathrm{i}} & \mathrm{I}=1,2, ., ., \mathrm{m} \\
\sum_{i=1}^{m} X i j=\mathrm{D}_{\mathrm{j}} & \mathrm{j}=1,2, ., ., \mathrm{n} \\
\mathrm{X}_{\mathrm{ij}} \geq 0 &
\end{array}
$$


Where:

$$
\begin{array}{ll}
\mathrm{C}_{\mathrm{ij}}{ }^{0}\left(\mathrm{x}_{\mathrm{ij}}\right), & 0 \leq \mathrm{x}_{\mathrm{ij}} \leq \mathrm{a}_{1} \\
\mathrm{C}_{\mathrm{ij}}{ }^{1}\left(\mathrm{x}_{\mathrm{ij}}\right), & \mathrm{a}_{1} \leq \mathrm{x}_{\mathrm{ij}} \leq \mathrm{a}_{\mathrm{l}+1} \\
\mathrm{C}_{\mathrm{ij}}{ }^{\mathrm{l}}\left(\mathrm{x}_{\mathrm{ij}}\right), & \mathrm{a}_{1} \leq \mathrm{x}_{\mathrm{ij}} \leq \mathrm{a}_{2} \\
\mathrm{C}_{\mathrm{ij}}{ }^{\mathrm{k}-1}\left(\mathrm{x}_{\mathrm{ij}}\right), & \mathrm{a}_{\mathrm{k}-1} \leq \mathrm{x}_{\mathrm{ij}} \leq \mathrm{a}_{\mathrm{k}} \\
\mathrm{C}_{\mathrm{ij}}{ }^{\mathrm{k}}\left(\mathrm{x}_{\mathrm{ij}}\right), & \mathrm{a}_{\mathrm{k}} \leq \mathrm{x}_{\mathrm{ij}} \leq \mathrm{b}=\max \left\{\mathrm{s}_{\mathrm{i}}, \mathrm{d}_{\mathrm{j}}\right\}
\end{array}
$$

and $1 .\left\{0, a_{1}, \ldots, a_{1}, \ldots, a_{k-1}, a_{k}, b\right\}$ is the partition of the interval $[0, b]$ into $k+1$ sub intervals; 2 . each $C_{\mathrm{ij}}^{1}$ is linear in the sub interval $\left[\mathrm{a}_{1}, \mathrm{a}_{1+1}\right]$. To solve this problem, as we can see from the structure of the cost function, it's impossible to directly apply the algorithm of the previous section for non differentiability of the total cost function hinders as to do so. But, since the function, also, has a simple structure and differentiability fails at discrete points, it can be easily approximated using differentiable functions like Chebshev, trigonometric or Legendre polynomials. We choose to approximate it by the so called shifted Legendre polynomials. These set of Legendre polynomials say $\left\{\mathrm{p}_{0}, \mathrm{p}_{1} \ldots, \mathrm{p}_{\mathrm{r}},\right\}$ is orthogonal in $[0,1]$ with respect to weight function $w(x)=1$, where the inner product on $C[0,1]$ is defined by

$$
<\mathrm{f}, \mathrm{g}>=\int_{0}^{1} f(x) g(x) d x, \text { for all } \mathrm{f}, \mathrm{g} \in \mathrm{C}[0,1]
$$

Where $C[0 ; 1]$ is the space of continuous functions on $[0,1]$. The first four of them are

$$
\begin{gathered}
\mathrm{p}_{0}(x)=1 \\
\mathrm{p}_{1}(\mathrm{x})=2 \mathrm{x}-1 \\
\mathrm{p} 2(\mathrm{x})=6 \mathrm{x} 2+6 \mathrm{x}+1 \\
\mathrm{p} 3(\mathrm{x})=20 \mathrm{x} 3+30 \mathrm{x} 2+12 \mathrm{x} ; 1
\end{gathered}
$$

and the others can be obtained from $\operatorname{p}_{\mathrm{r}}(x)=\frac{1}{2^{r} !} \frac{d^{r}}{d x^{2}}\left[\left(\mathrm{x}^{2}-1\right)^{\mathrm{r}}\right]$. Then, the space spanned by $\left\{\mathrm{p}_{0}, \mathrm{p}_{1} \ldots, \mathrm{p}_{\mathrm{r}}\right\}$ is a subspace of $C[0,1]$. Hence, given any $\mathrm{f}(x) \in C[0,1]$, we can find a unique least square approximation of $f$ in the subspace. Note that every element of the subspace spanned $\left\{\mathrm{p}_{0}, \mathrm{p}_{1}, \ldots, \mathrm{p}_{\mathrm{r}}\right\}$ is at least twice differentiable. The least square approximation of any function $f(x)$ with $r$ of these polynomials in $[0,1]$ is given by $\mathrm{f}(\mathrm{x})=\mathrm{a}_{0} \mathrm{p}_{0}(\mathrm{x})+\mathrm{a}_{1} \mathrm{p}_{1}(\mathrm{x})+\ldots+$ 
$\mathrm{a}_{\mathrm{i}} \mathrm{p}_{\mathrm{i}}(\mathrm{x})+\ldots+\mathrm{a}_{\mathrm{r}} \mathrm{p}_{\mathrm{r}}(\mathrm{x})$ where ai $=\frac{\int_{0}^{1} P i F(x) d x}{\int_{0}^{1}[P i(x)] 2 d x}, \quad \mathrm{i}=0,1, \ldots$, r. To approximate our functions $\mathrm{C}_{\mathrm{ij}}\left(\mathrm{x}_{\mathrm{ij}}\right)$, in the same manner, we define a one to one correspondence between $[0, \mathrm{~b}]$ to $[0,1]$ by

$$
\begin{gathered}
\mathrm{g}:[0, \mathrm{~b}] \rightarrow[0,1] \\
\mathrm{g}\left(\mathrm{x}_{\mathrm{ij}}\right)=\frac{1}{b} \mathrm{x}_{\mathrm{ij}}
\end{gathered}
$$

That is, we substitute $\mathrm{x}_{\mathrm{ij}}$ by $\frac{1}{b} \mathrm{x}_{\mathrm{ij}}$ so that it's domain will be $[0,1]$ then we have,

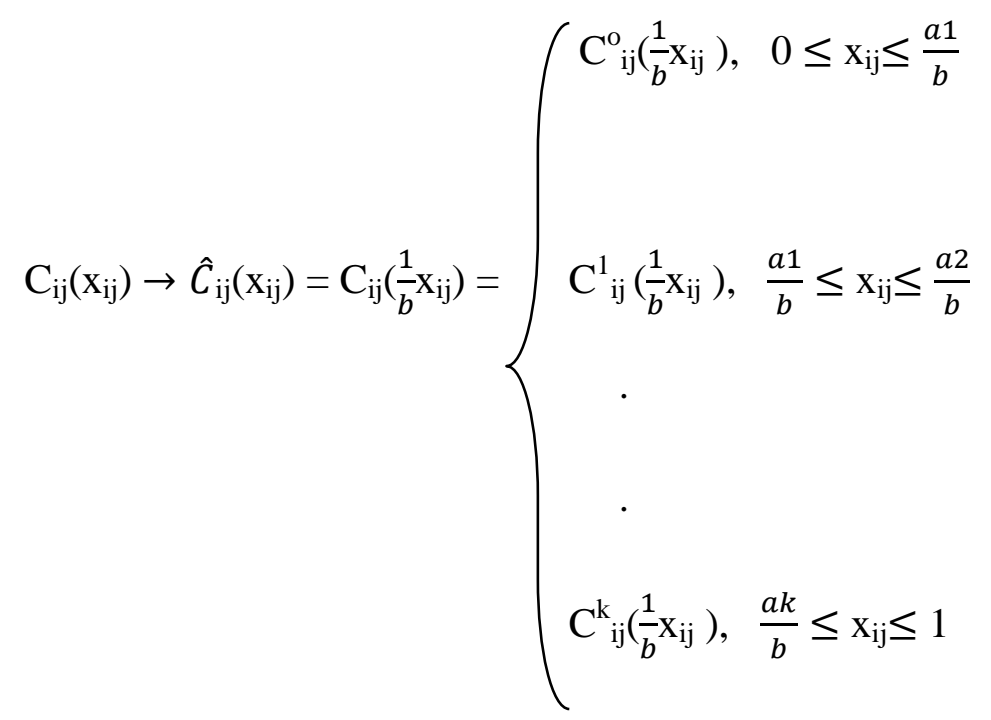

Now, after approximating $\hat{C}_{\mathrm{ij}} \mathrm{x}_{\mathrm{ij}}$ by the shifted Legendre polynomials on $[0,1]$, assume we have found it's best approximation $\hat{C}_{\mathrm{ij}}\left(\mathrm{x}_{\mathrm{ij}}\right)$. Then, substituting back the $\mathrm{x}_{\mathrm{ij}}$ in $\mathrm{\epsilon}_{\mathrm{ij}} \mathrm{by} \mathrm{bx}_{\mathrm{ij}}$ gives us the approximation to $\mathrm{Cij}\left(\mathrm{x}_{\mathrm{ij}}\right)$ over [0,b]. Therefore the best approximation of $\mathrm{C}_{\mathrm{ij}}\left(\mathrm{x}_{\mathrm{ij}}\right)$ over $[0, \mathrm{~b}]$ will be $\bar{C}_{\mathrm{ij}}\left(\mathrm{x}_{\mathrm{ij}}\right)=\hat{C}_{\mathrm{ij}}\left(\mathrm{bx}_{\mathrm{ij}}\right)$, which has continuous derivatives. Consequently, we solve the problem

$$
\begin{aligned}
& \operatorname{Min} \sum_{i=1}^{n} \sum_{j=1}^{m} \bar{C}\left(\mathrm{x}_{\mathrm{ij}}\right)=\sum_{l=0}^{2} \sum_{i=1}^{n} \sum_{j=1}^{m} a_{\mathrm{p}} \mathrm{p}_{1}\left(\mathrm{x}_{\mathrm{ij}}\right) \\
& \text { s. } \mathrm{t} \sum_{j=1}^{n} x i j=\frac{s i}{b} \\
& \sum_{i=1}^{n} x i j=\frac{d j}{b} \\
& \mathrm{i}=1,2, \ldots, \mathrm{n} \quad \text { and } \mathrm{j}=1,2, \ldots, \mathrm{m}
\end{aligned}
$$

Using exactly the same procedure as the previous case. 


\subsection{Convex Transportation Problem}

This case may arise when the objective function is composed of not only the unit transportation cost but also of production cost related to each commodity, or in the case when the distance from each source to each destination is not fixed. The problem can be formulated as:

$$
\begin{aligned}
& \operatorname{Min} C(\mathrm{x}) \\
& \text { s.t } A \mathrm{x}=b \\
& \mathrm{x} \geq 0
\end{aligned}
$$

Where $\mathrm{C}(\mathrm{x})$ is convex, continuous and has continuous first order partial derivatives.

\subsubsection{The Convex Simplex solution procedure for Transportation Problem}

In the case when the cost function is convex, the minimum point may not be attained necessarily at an extreme; it may be found before reaching a boundary of the feasible set. What precisely happens is that there may be non basic variable with positive allocation while non of the basis is driven to zero. To solve this problem, we use the idea of the convex simplex algorithm of Zangwill (1967) which was originally designed to take care of convex and pseudoconvex problem with linear constraints. Actually the original procedure is used to look for a local optimal solution for any other linearly constrained programming problem. We use the special structure of transportation problem in the procedure so as to make it efficient for our particular problem. The method reduces to the ordinary transportation simplex algorithm whenever the objective is linear, to the method of Beal when it is quadratic and to the above concave simplex procedure when the function is concave.

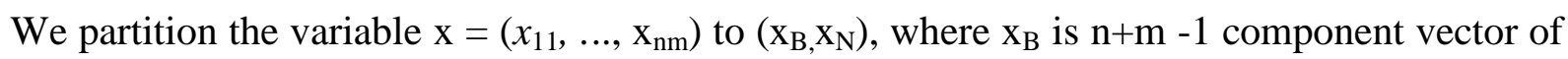
basic variables and $x_{N}$ is $\left.n m-(n+m-1)\right)$ component vector of non basic variables, corresponding to the $(n+m-1) X(n+m-1)$ basic sub matrix and $(n+m-1) X(n m-(n+m-1))$ non basic sub matrix of $\mathrm{A}$.

Suppose we have the initial basic feasible solution $\bar{x}_{0}$.In the procedure what we do is to find a mechanism in which non optimal basic solution $\bar{x}$ at a given iteration is improved until it satisfies the KKT conditions which are also sufficient conditions for convex transportation 
problem, i. e, until for each cell we have $\mathrm{x}_{\mathrm{ij}}\left(\frac{\partial f(\bar{x})}{\partial X \mathrm{ij}}-\left(\mathrm{u}_{\mathrm{i}}+\mathrm{v}_{\mathrm{j}}\right)\right)=0$ and $\frac{\partial f(\bar{x})}{\partial X \mathrm{ij}}-\left(\mathrm{u}_{\mathrm{i}}+\mathrm{v}_{\mathrm{j}}\right) \geq 0$. Since we have each basic variable $\mathrm{x}_{\mathrm{Bij}}>0$, the above complementary slackness condition implies that for each basic cell, we must have $\left.\frac{\partial f(\bar{x})}{\partial X B \mathrm{ij}}-\left(\mathrm{u}_{\mathrm{i}}+\mathrm{v}_{\mathrm{j}}\right)\right)=0, \mathrm{x}_{\mathrm{Bij}}{ }^{-}$basic variable. Since we have $n+m-1$ of such equations, by letting $\mathrm{u}_{1}=0$ we obtain all the values of $\mathrm{u}_{\mathrm{i}}$ and $\mathrm{v}_{\mathrm{j}}$ as we have done exactly for the concave and linear cases. Now for a non basic cell, at a feasible iterate point $\bar{x}$; we may have:

$$
\begin{aligned}
& \frac{\partial f(\bar{x})}{\partial X \mathrm{ij}}-\left(\mathrm{u}_{\mathrm{i}}+\mathrm{v}_{\mathrm{j}}\right)>0, \mathrm{x}_{\mathrm{ij}}\left(\frac{\partial f(\bar{x})}{\partial X \mathrm{ij}}-\left(\mathrm{u}_{\mathrm{i}}+\mathrm{v}_{\mathrm{j}}\right)\right)>0, \\
& \frac{\partial f(\bar{x})}{\partial X \mathrm{ij}}-\left(\mathrm{u}_{\mathrm{i}}+\mathrm{v}_{\mathrm{j}}\right)<0, \mathrm{x}_{\mathrm{ij}}\left(\frac{\partial f(\bar{x})}{\partial X \mathrm{ij}}-\left(\mathrm{u}_{\mathrm{i}}+\mathrm{v}_{\mathrm{j}}\right)\right)<0, \\
& \frac{\partial f(\bar{x})}{\partial X \mathrm{ij}}-\left(\mathrm{u}_{\mathrm{i}}+\mathrm{v}_{\mathrm{j}}\right)=0, \mathrm{x}_{\mathrm{ij}}\left(\frac{\partial f(\bar{x})}{\partial X \mathrm{ij}}-\left(\mathrm{u}_{\mathrm{i}}+\mathrm{v}_{\mathrm{j}}\right)\right)=0
\end{aligned}
$$

Or for non basic $\mathrm{x}_{\mathrm{ij}}$, we may have: $\frac{\partial f(\bar{x})}{\partial X \mathrm{ij}}-\left(\mathrm{u}_{\mathrm{i}}+\mathrm{v}_{\mathrm{j}}\right) \geq 0, \mathrm{x}_{\mathrm{ij}}\left(\frac{\partial f(\bar{x})}{\partial X \mathrm{ij}}-\left(\mathrm{u}_{\mathrm{i}}+\mathrm{v}_{\mathrm{j}}\right)\right)=0$. From the KKT conditions given earlier, the last case occurs when $\bar{x}$ is optimal. But if the solution $\bar{x}$ falls on either of the other three, it must be improved as follows. Let $I J=\left\{\mathrm{ij}: \mathrm{X}_{\mathrm{ij}}\right.$ is non basic variable $\}$ and suppose that we are in the $\mathrm{k}^{\text {th }}$ iteration. We first begin by computing;

$$
\begin{aligned}
& \frac{\partial z}{\partial X r l}=\min \left\{\frac{\partial f(\bar{x})}{\partial X i j}-\mathrm{u}_{\mathrm{i}}-\mathrm{v}_{\mathrm{j}}\right\} \mathrm{ij} \in \mathrm{IJ} \\
& \mathrm{Xs}_{\mathrm{t}} \frac{\partial z}{\partial X r l}=\max \left\{\mathrm{x}_{\mathrm{ij}}\left(\frac{\partial f(\bar{x})}{\partial X i j}-\mathrm{u}_{\mathrm{i}}-\mathrm{v}_{\mathrm{j}}\right)\right\} \mathrm{ij} \in \mathrm{IJ}
\end{aligned}
$$

Here we don't want to improve (decrease) a positive - valued non basic variable $\mathrm{x}_{\mathrm{ij}}$ unless its partial derivative is positive. Therefore we only focus on positive values of the product $\frac{\partial z}{\partial X i j} \mathrm{x}_{\mathrm{ij}}$. Now the variables to be adjusted are selected as:

Case 1 If $\frac{\partial z}{\partial X r l} \geq 0$ and $x s t\left(\frac{\partial z}{\partial X s t}\right)>0$.

Decrease $\mathrm{x}_{\mathrm{st}}$ by the value $\theta$ using the transportation table as in the linear and concave cases. Let $y^{\mathrm{k}}=\left(\mathrm{y}^{\mathrm{k}}{ }_{11}, \mathrm{y}^{\mathrm{k}}{ }_{12}, \ldots, \mathrm{y}^{\mathrm{k}}{ }_{\mathrm{nm}}\right)$ be the value of $\bar{x}^{\mathrm{k}}=\left(\bar{x}^{\mathrm{k}}{ }_{11}, \ldots, \bar{x}^{\mathrm{k}}{ }_{\mathrm{nm}}\right)$ after making the necessary adjustment by adding and subtracting $\theta$ in the loop containing $\mathrm{x}_{\mathrm{st}}$ so that all the constraints are satisfied. By doing so, either $\mathrm{x}_{\mathrm{st}}$ itself or a basic variable say $\mathrm{x}_{\mathrm{Bst}}$ will be driven to zero. Now 
$\mathrm{y}^{\mathrm{k}}$ may not be the next iterate point; since the function is convex, a better point could be found before reaching $\mathrm{y}^{\mathrm{k}}$ to check this, we solve problem;

$$
\mathrm{f}\left(\bar{x}^{\mathrm{k}+1}\right)=\min \left\{\mathrm{f}\left(\beta \bar{x}^{\mathrm{k}}+(1-\beta) \mathrm{y}^{\mathrm{k}}: 0 \leq \beta \leq 1\right\}\right.
$$

and get $\bar{x}^{\mathrm{k}+1}=\bar{\beta} \bar{x}^{\mathrm{k}}+(1-\bar{\beta}) \mathrm{y}^{\mathrm{k}}$ where $\bar{\beta}$ is the optimal solution of equation 3.5 . Before the next iteration, if $\bar{x}^{\mathrm{k}+1}=\mathrm{y}^{\mathrm{k}}$ and if a basic variable became zero during the adjustment made, we change the basis. If $\bar{x}^{\mathrm{k}+1} \neq \mathrm{y}^{\mathrm{k}}$ or if $\bar{x}^{\mathrm{k}+1}=\mathrm{y}^{\mathrm{k}}$ and $\mathrm{x}_{\mathrm{st}}$ is driven to zero, we don't change the basis by substituting the leaving basic variable by $\mathrm{x}_{\mathrm{st}}$.

Case 2 If $\frac{\partial z}{\partial X r l}<0$ and $\mathrm{x}_{\mathrm{st}}\left(\frac{\partial z}{\partial X s t}\right) \leq 0$.

In this case the value of $\mathrm{x}_{\mathrm{rl}}$ should be increased by $\theta$ and then we find $\mathrm{y}^{\mathrm{k}}$, where $\theta$ and $\mathrm{y}^{\mathrm{k}}$ are defined as in the case 1 .

Note that: as we increase the value of $\mathrm{x}_{\mathrm{rl}}$ one of the basic variables, say, $\mathrm{x}_{\mathrm{Bt}}$ will be driven to zero, and this is the exit criteria of the linear and concave transportation simplex algorithm and $\mathrm{y}^{\mathrm{k}}$ would have been the next iterate point of the procedure. But now after solving for $\bar{x}^{\mathrm{k}+1}$ from 3.5 , before going to the next iteration, we will have the following possibilities: If $\bar{x}^{\mathrm{k}+1}$ $=\mathrm{y}^{\mathrm{k}}$, we change the former basis, substitute $\mathrm{x}_{\mathrm{Bt}}$ by $\mathrm{x}_{\mathrm{r}}$; if $\bar{x}^{\mathrm{k}+1} \neq \mathrm{y}^{\mathrm{k}}$, we do not change the basis. All the basic variables outside of the loop will remain unchanged.

Case 3 If $\frac{\partial z}{\partial X r l}<0$ and $\mathrm{x}_{\mathrm{st}}\left(\frac{\partial z}{\partial X s t}\right)>0$

In this case either we decrease $\mathrm{x}_{\mathrm{st}}$ as in the case 1 or increase $\mathrm{x}_{\mathrm{rl}}$ according to Case 2 .

\subsection{The Transportation Convex Simplex Algorithm}

Now we write the formal algorithm for solving the convex transportation problem.

- Initialization: Find the initial basic feasible solution.

- Iteration

- Step 1: Determine all $\mathrm{u}_{\mathrm{i}}$ and $\mathrm{v}_{\mathrm{j}}$ from $\frac{\partial f(\bar{x})}{\partial X B \mathrm{ij}}-\mathrm{u}_{\mathrm{i}}-\mathrm{v}_{\mathrm{j}}=0$ for each basic cell. 
- Step 2: For each non basic cell, calculate: $\frac{\partial z}{\partial X r l}=\min \left\{\frac{\partial f(\bar{x})}{\partial X i j}-\mathrm{u}_{\mathrm{i}}-\mathrm{v}_{\mathrm{j}}\right\} ; \mathrm{xs}_{\mathrm{t}} \frac{\partial z}{\partial X r l}=\max \left\{\mathrm{x}_{\mathrm{ij}}(\right.$ $\left.\left.\frac{\partial f(\bar{x})}{\partial X i j}-\mathrm{u}_{\mathrm{i}}-\mathrm{v}_{\mathrm{j}}\right)\right\}$ If $\frac{\partial z}{\partial X r l} \geq 0$ and $\mathrm{x}_{\mathrm{st}}\left(\frac{\partial z}{\partial X s t}\right)=0$. Stop. Otherwise go to Step 3 .

- Step 3: Determine the non basic variable to change. Decrease $\mathrm{x}_{\mathrm{st}}$ according to case 1 if $\frac{\partial z}{\partial X r l} \geq 0$ and $\mathrm{x}_{\mathrm{st}}\left(\frac{\partial z}{\partial X s t}\right)>0$. Increase $\mathrm{x}_{\mathrm{rl}}$ according to case 2 if $\frac{\partial z}{\partial X r l}<0$ and $\mathrm{x}_{\mathrm{st}}\left(\frac{\partial z}{\partial X s t}\right) \leq$ 0 . Either increase $\mathrm{x}_{\mathrm{rl}}$ or decrease $\mathrm{x}_{\mathrm{st}}$ if $\frac{\partial z}{\partial X r l}<0$ and $\mathrm{x}_{\mathrm{st}}\left(\frac{\partial z}{\partial X s t}\right)>0$.

- Step 4: Find the values of $\mathrm{y}^{\mathrm{k}}$, by means of $\theta$, and $\bar{x}^{\mathrm{k}+1}$, from 3.5. If $\mathrm{y}^{\mathrm{k}}=\bar{x}^{\mathrm{k}+1}$ and a basic variable is driven to zero, change the basis. Otherwise do not change the basis. $\bar{x}^{\mathrm{k}}=\bar{x}^{\mathrm{k}+1}$. Go to step 1 .

\section{Case study}

In this section, we shall consider a computational study of the above solution procedures. Emphasis will be given to a transportation problem where discounts are given to volume on quantity of goods transported which is concave in nature. Data from the Multi-Plan Limited shall be examined.

\subsection{Data collection and analysis}

The Multi-Plan Limited, a distributor of various kinds of drinks located in Accra, purchase from three manufacturing companies in different places and sell the same to four market segments in Ghana. The cost of purchasing and transporting the drinks from the traders place to the market centres is given in Table 1 below. 
Table 1 - Cost of transporting the drinks to the various market zones

\begin{tabular}{|c|c|c|c|c|c|c|c|}
\hline & \multirow{2}{*}{ AVAILABILITY } & \multirow{2}{*}{$\begin{array}{l}\text { LOADING } \\
\text { AND } \\
\text { PACKAGING }\end{array}$} & \multicolumn{4}{|c|}{ MARKET SEGMENTS } & \multirow[t]{2}{*}{ SUPPLY } \\
\hline & & & A & $\mathrm{B}$ & $\mathrm{C}$ & $\mathrm{D}$ & \\
\hline P. RED & 15,000 & 3,000 & 12,000 & 7,000 & 1,000 & 17,000 & 15,000 \\
\hline OVIDIO & 25,000 & 2,000 & 5,000 & 4,000 & 6,000 & 1,000 & 25,000 \\
\hline MERLOT & 10,000 & 600 & 400 & 8,400 & 4,400 & 2,400 & 10,000 \\
\hline \multicolumn{3}{|c|}{ REQUIREMENT OF DRINKS } & 20,000 & 10,000 & 8,000 & 12,000 & \\
\hline
\end{tabular}

All values in Table 1 apart from requirements and supply are in cedi monetary value. The policy of the company allows discounts on each box transported from source to destination and it is directly related to the unit commodity purchased and transported, and the percentage discounts are shown in Table 2 below.

Table 2 - Percentage discounts

\begin{tabular}{|l|c|c|c|c|}
\hline & $\mathrm{A}$ & $\mathrm{B}$ & $\mathrm{C}$ & $\mathrm{D}$ \\
\hline P. RED & 0.02 & 0.01 & 0.04 & 0.07 \\
\hline OVIDIO & 0.01 & 0.04 & 0.03 & 0.02 \\
\hline MERLOT & 0.005 & 0.03 & 0.015 & 0.01 \\
\hline
\end{tabular}

The problem is to determine how many boxes of each product to be transported from the source to each destination on a monthly basis in order to minimize the total transportation cost.

Table 3 - Forming the transportation tableau

\begin{tabular}{|l|c|c|c|c|c|}
\hline & A & B & C & D & SUPPLY \\
\hline P. RED & 15 & 10 & 4 & 20 & 15 \\
\hline OVIDIO & 7 & 6 & 8 & 3 & 25 \\
\hline MERLOT & 1 & 9 & 5 & 3 & 10 \\
\hline DEMAND & 20 & 10 & 8 & 12 & $\mathbf{5 0}$ \\
\hline
\end{tabular}


To form transportation tableau, let $i=$ product to be shipped; $j=$ destination of each product; $s_{i}=$ the capacity of source node $i ; d_{j}=$ the demand of destination $j ; x_{\mathrm{ij}}=$ the total capacity from source $i$ to destination $j ; C_{\mathrm{ij}}=$ the per unit cost of transporting commodity from $i$ to destination $j$. If we suppose that discount is given on each box transported from $i$ to $j$ then the non linear transportation problem can be formulated as:

$$
\begin{array}{cc}
\text { Minimize } & 15 x_{11}+10 x_{12}+4 x_{13}+20 x_{14} \\
& 7 x_{21}+6 x_{22}+8 x_{23}+3 x_{24} \\
& x_{31}+9 x_{32}+5 x_{33}+3 x_{34}
\end{array}
$$

Subject to

$$
\begin{aligned}
& \mathrm{x}_{11}+\mathrm{x}_{12}+\mathrm{x}_{13}+\mathrm{x}_{14}=15 \\
& \mathrm{x}_{21}+\mathrm{x}_{22}+\mathrm{x}_{23}+\mathrm{x}_{24}=25 \\
& \mathrm{x}_{31}+\mathrm{x}_{32}+\mathrm{x}_{33}+\mathrm{x}_{34}=10 \\
& \mathrm{x}_{11}+\mathrm{x}_{21}+\mathrm{x}_{31}=20 \\
& \mathrm{x}_{12}+\mathrm{x}_{22}+\mathrm{x}_{32}=10 \\
& \mathrm{x}_{13}+\mathrm{x}_{23}+\mathrm{x}_{33}=8 \\
& \mathrm{x}_{14}+\mathrm{x}_{24}+\mathrm{x}_{34}=12
\end{aligned}
$$

where

$$
\begin{array}{ll}
\mathrm{C}_{11} \mathrm{x}_{11}=15 \mathrm{x}_{11}-\mathrm{p}_{11} \mathrm{x}^{2}{ }_{11} & \mathrm{C}_{22} \mathrm{x}_{22}=6 \mathrm{x}_{22}-\mathrm{p}_{22} \mathrm{x}^{2}{ }_{22} \\
\mathrm{C}_{12} \mathrm{x}_{12}=10 \mathrm{x}_{12}-\mathrm{p}_{12} \mathrm{x}^{2}{ }_{12} & \mathrm{C}_{23} \mathrm{x}_{23}=8 \mathrm{x}_{23}-\mathrm{p}_{23} \mathrm{x}^{2}{ }_{23} \\
\mathrm{C}_{13} \mathrm{x}_{13}=4 \mathrm{x}_{13}-\mathrm{p}_{13} \mathrm{x}^{2}{ }_{13} & \mathrm{C}_{24} \mathrm{x}_{24}=3 \mathrm{x}_{24}-\mathrm{p}_{24} \mathrm{x}_{24}^{2} \\
\mathrm{C}_{14} \mathrm{x}_{14}=20 \mathrm{x}_{14}-\mathrm{p}_{14} \mathrm{x}^{2}{ }_{14} & \mathrm{C}_{31} \mathrm{x}_{31}=\mathrm{x}_{31}-\mathrm{p}_{31} \mathrm{x}_{31}^{2} \\
\mathrm{C}_{21} \mathrm{x}_{21}=7 \mathrm{x}_{21}-\mathrm{p}_{21} \mathrm{x}^{2}{ }_{21} & \mathrm{C}_{32} \mathrm{x}_{32}=9 \mathrm{x}_{32}-\mathrm{p}_{32} \mathrm{x}^{2}{ }_{32} \\
\mathrm{C}_{33} \mathrm{x}_{33}=5 \mathrm{x}_{33}-\mathrm{p}_{33} \mathrm{x}^{2}{ }_{33} & \mathrm{C}_{34} \mathrm{x}_{34}=3 \mathrm{x}_{34}-\mathrm{p}_{34} \mathrm{x}^{2}{ }_{34}
\end{array}
$$

If we allow the discounts on each transported product $i$ from the source to each of the destinations $\mathrm{j}$ as given in Table 2, the cost function become:

$$
\begin{array}{ll}
\mathrm{C}_{11} \mathrm{x}_{11}=15 \mathrm{x}_{11}-0.02 \mathrm{x}^{2}{ }_{11} & \mathrm{C}_{22} \mathrm{x}_{22}=6 \mathrm{x}_{22}-0.04 \mathrm{x}^{2}{ }_{22} \\
\mathrm{C}_{12} \mathrm{x}_{12}=10 \mathrm{x}_{12}-0.01 \mathrm{x}^{2}{ }_{12} & \mathrm{C}_{23} \mathrm{x}_{23}=8 \mathrm{x}_{23}-0.03 \mathrm{x}^{2}{ }_{23} \\
\mathrm{C}_{13} \mathrm{x}_{13}=4 \mathrm{x}_{13}-0.04 \mathrm{x}_{13}^{2} & \mathrm{C}_{24} \mathrm{x}_{24}=3 \mathrm{x}_{24}-0.02 \mathrm{x}^{2}{ }_{24} \\
\mathrm{C}_{14} \mathrm{x}_{14}=20 \mathrm{x}_{14}-0.07 \mathrm{x}^{2}{ }_{14} & \mathrm{C}_{31} \mathrm{x}_{31}=\mathrm{x}_{31}-0.005 \mathrm{x}^{2}{ }_{31} \\
\mathrm{C}_{21} \mathrm{x}_{21}=7 \mathrm{x}_{21}-0.01 \mathrm{x}^{2}{ }_{21} & \mathrm{C}_{32} \mathrm{x}_{32}=9 \mathrm{x}_{32}-0.03 \mathrm{x}_{32}^{2} \\
\mathrm{C}_{33} \mathrm{x}_{33}=5 \mathrm{x}_{33}-0.04 \mathrm{x}_{33}{ }_{33} & \mathrm{C}_{34} \mathrm{x}_{34}=3 \mathrm{x}_{34}-0.01 \mathrm{x}_{34}^{2}
\end{array}
$$

Using the West Corner rule we get the initial basic solution. The solution tableau is as shown below: 
Table 4 - Solution tableau

\begin{tabular}{|c|c|c|c|c|c|c|c|c|c|}
\hline & \multicolumn{2}{|l|}{$\mathrm{A}$} & \multicolumn{2}{|l|}{ B } & \multicolumn{2}{|l|}{$\mathrm{C}$} & \multicolumn{2}{|l|}{ D } & SUPPLY \\
\hline P. RED & 15 & 15 & & 10 & & 4 & & 20 & 15 \\
\hline OVIDIO & 5 & 7 & 10 & 6 & 8 & 8 & 2 & 3 & 25 \\
\hline MERLOT & & 1 & & 9 & & 5 & 10 & 3 & 10 \\
\hline DEMAND & 20 & & 10 & & 8 & & 12 & & 50 \\
\hline
\end{tabular}

The initial basic feasible solution is: $\bar{x}=\left(\mathrm{x}_{\mathrm{B} 11}, \mathrm{x}_{12}, \mathrm{x}_{13}, \mathrm{x}_{14}, \mathrm{x}_{\mathrm{B} 21}, \mathrm{x}_{\mathrm{B} 22}, \mathrm{x}_{\mathrm{B} 23}, \mathrm{x}_{24}, \mathrm{x}_{31}, \mathrm{x}_{32}, \mathrm{x}_{33}\right.$, $\left.\mathrm{x}_{\mathrm{B} 34}\right)$. This from the table is given as $\bar{x}=(15,0,0,0,5,10,8,2,0,0,0,10)$ in thousands with the total transportation cost of Cost $=(1,500 * 15)+(5000 * 5)+(10,000 * 6)+(8,000 * 8)+$ $(2,000 * 3)+(10,000 * 2)$. Total Cost $=\mathrm{GH} \phi 400,000.00$.

Now, we use the KKT optimality conditions to improve upon our solution. The partial derivatives at $\bar{x}$ for the cost function are given as:

$$
\begin{array}{lrrrr}
\frac{\partial f(x)}{\partial x_{11}}=14.4 & \frac{\partial f(x)}{\partial x_{12}}=10 & \frac{\partial f(x)}{\partial x_{13}}=4 & \frac{\partial f(x)}{\partial x_{14}}=20 \\
\frac{\partial f(x)}{\partial x_{21}}=6.9 & \frac{\partial f(x)}{\partial x_{22}}=5.2 & \frac{\partial f(x)}{\partial x_{23}}=7.52 & \frac{\partial f(x)}{\partial x_{24}}=2.92 \\
\frac{\partial f(x)}{\partial x_{31}}=1 & \frac{\partial f(x)}{\partial x_{32}}=9 & \frac{\partial f(x)}{\partial x_{33}}=5 & \frac{\partial f(x)}{\partial x_{34}}=1.8
\end{array}
$$

Now we find from the cost equation of the occupied cell;

$$
\frac{\partial Z}{\partial x_{B i j}}=\frac{\partial f(x)}{\partial x_{B i j}}-\mathrm{u}_{\mathrm{i}}-\mathrm{v}_{\mathrm{j}}=0
$$

Thus,

$$
\begin{array}{cc}
\frac{\partial f(x)}{\partial x_{B i j}}=\mathrm{u}_{\mathrm{i}}+\mathrm{v}_{\mathrm{j}} \\
\mathrm{u}_{1}+\mathrm{v}_{1}=14.4 & \mathrm{u}_{1}+\mathrm{v}_{2}=10 \quad \mathrm{u}_{2}+\mathrm{v}_{2}=5.2 \\
\mathrm{u}_{2}+\mathrm{v}_{4}=2.92 & \mathrm{u}_{2}+\mathrm{v}_{1}=6.9 \quad \mathrm{u}_{2}+\mathrm{v}_{3}=7.52 \quad \mathrm{u}_{3}+\mathrm{v}_{4}=1.8
\end{array}
$$

Letting $\mathrm{u}_{1}=0$, from the equations we have: 
$\mathrm{u}_{1}=0, \quad \mathrm{u}_{2}=-7.5, \quad \mathrm{u}_{3}=-8.62, \quad \mathrm{v}_{1}=14.4, \mathrm{v}_{2}=12.7, \mathrm{v}_{3}=15.02$, and $\mathrm{v}_{4}=10.42$

We find the net evaluation factor or the reduced costs for the non-basic variables.

$$
\begin{aligned}
\frac{\partial Z}{\partial x_{12}}=\frac{\partial f(x)}{\partial x_{12}}-\mathrm{u}_{1}-\mathrm{v}_{2}=-2.7 & \frac{\partial Z}{\partial x_{13}}=\frac{\partial f(x)}{\partial x_{13}}-\mathrm{u}_{1}-\mathrm{v}_{3}=-11.02 \\
\frac{\partial Z}{\partial x_{14}}=\frac{\partial f(x)}{\partial x_{14}}-\mathrm{u}_{1}-\mathrm{v}_{4}=9.58 & \frac{\partial Z}{\partial x_{31}}=\frac{\partial f(x)}{\partial x_{31}}-\mathrm{u}_{3}-\mathrm{v}_{1}=-4.78 \\
\frac{\partial Z}{\partial x_{32}}=\frac{\partial f(x)}{\partial x_{32}}-\mathrm{u}_{3}-\mathrm{v}_{2}=4.92 & \frac{\partial Z}{\partial x_{33}}=\frac{\partial f(x)}{\partial x_{33}}-\mathrm{u}_{3}-\mathrm{v}_{3}=-1.4
\end{aligned}
$$

The presence of negative values for the reduced cost signifies non optimality; hence we readjust. From the above, the minimum reduced costs for the non-basic variable is $\mathrm{x}_{13}$. Therefore $\mathrm{x}_{13}$ should enter the basis since it is the most negative reduced cost.

We then move on to next iteration. At the end of this stage of iteration, the basic feasible solution is $\bar{x}^{1}=(15,0,0,0,5,10,8,2,0,0,0,10)$. After adjusting the values $\mathrm{x}_{23}$ entered the solution. Next we find the cost equation for the occupy cell.

$$
\frac{\partial Z}{\partial x_{B i j}}=\frac{\partial f(x)}{\partial x_{B i j}}-\mathrm{u}_{\mathrm{i}}-\mathrm{v}_{\mathrm{j}}=0
$$

Thus,

$$
\begin{array}{rcc}
\frac{\partial f(x)}{\partial x_{B i j}}=\mathrm{u}_{\mathrm{i}}+\mathrm{v}_{\mathrm{j}} & \\
\mathrm{u}_{1}+\mathrm{v}_{1}=14.4 & \mathrm{u}_{1}+\mathrm{v}_{3}=4 & \mathrm{u}_{2}+\mathrm{v}_{1}=6.9 \\
\mathrm{u}_{2}+\mathrm{v}_{2}=5.2 & \mathrm{u}_{2}+\mathrm{v}_{4}=2.92 & \mathrm{u}_{3}+\mathrm{v}_{4}=1.8
\end{array}
$$

Letting $\mathrm{u}_{1}=0$, from the equations we have;

$$
\mathrm{u}_{1}=0, \quad \mathrm{u}_{2}=-7.5, \quad \mathrm{u}_{3}=-8.62, \quad \mathrm{v}_{1}=14.4, \mathrm{v}_{2}=12.7, \mathrm{v}_{3}=4, \text { and } \mathrm{v}_{4}=10.42
$$

The net evaluation factor or the reduced costs for the non-basic variables is;

$$
\frac{\partial Z}{\partial x_{12}}=\frac{\partial f(x)}{\partial x_{12}}-\mathrm{u}_{1}-\mathrm{v}_{2}=-2.7 \quad \frac{\partial Z}{\partial x_{23}}=\frac{\partial f(x)}{\partial x_{23}}-\mathrm{u}_{2}-\mathrm{v}_{3}=11.02
$$




$$
\begin{aligned}
\frac{\partial Z}{\partial x_{14}}=\frac{\partial f(x)}{\partial x_{14}}-\mathrm{u}_{1}-\mathrm{v}_{4}=9.58 & \frac{\partial Z}{\partial x_{31}}=\frac{\partial f(x)}{\partial x_{31}}-\mathrm{u}_{3}-\mathrm{v}_{1}=-4.78 \\
\frac{\partial Z}{\partial x_{32}}=\frac{\partial f(x)}{\partial x_{32}}-\mathrm{u}_{3}-\mathrm{v}_{2}=4.92 & \frac{\partial Z}{\partial x_{33}}=\frac{\partial f(x)}{\partial x_{33}}-\mathrm{u}_{3}-\mathrm{v}_{3}=9.62
\end{aligned}
$$

The presence of negative values for the reduced cost signifies non optimality; hence we readjust. From the above, the minimum reduced costs for the non-basic variable is $\mathrm{x}_{31}$. Therefore $\mathrm{x}_{31}$ should enter the basis since it is the most negative reduced cost.

We then move on to next iteration. At the end of this stage of iteration, the basic feasible solution is $\bar{x}^{2}=(7,0,8,0,13,10,0,2,0,0,0,10)$. Next we find the cost equation for the occupy cell.

$$
\frac{\partial Z}{\partial x_{B i j}}=\frac{\partial f(x)}{\partial x_{B i j}}-\mathrm{u}_{\mathrm{i}}-\mathrm{v}_{\mathrm{j}}=0
$$

Thus,

$$
\begin{array}{rlr}
\frac{\partial f(x)}{\partial x_{B i j}}=\mathrm{u}_{\mathrm{i}}+\mathrm{v}_{\mathrm{j}} & \\
\mathrm{u}_{1}+\mathrm{v}_{1}=14.4 & \mathrm{u}_{1}+\mathrm{v}_{3}=4 & \mathrm{u}_{2}+\mathrm{v}_{1}=6.9 \\
\mathrm{u}_{2}+\mathrm{v}_{2}=5.2 & \mathrm{u}_{2}+\mathrm{v}_{4}=2.92 & \mathrm{u}_{3}+\mathrm{v}_{4}=1.8
\end{array}
$$

Letting $\mathrm{u}_{1}=0$, from the equations we have;

$$
\mathrm{u}_{1}=0, \quad \mathrm{u}_{2}=-7.5, \quad \mathrm{u}_{3}=-8.62, \quad \mathrm{v}_{1}=14.4, \mathrm{v}_{2}=12.7, \mathrm{v}_{3}=4, \text { and } \mathrm{v}_{4}=10.42
$$

The net evaluation factor or the reduced costs for the non-basic variables is;

$$
\begin{aligned}
\frac{\partial Z}{\partial x_{12}}=\frac{\partial f(x)}{\partial x_{12}}-\mathrm{u}_{1}-\mathrm{v}_{2}=-2.7 & \frac{\partial Z}{\partial x_{23}}=\frac{\partial f(x)}{\partial x_{23}}-\mathrm{u}_{2}-\mathrm{v}_{3}=11.02 \\
\frac{\partial Z}{\partial x_{14}}=\frac{\partial f(x)}{\partial x_{14}}-\mathrm{u}_{1}-\mathrm{v}_{4}=9.58 & \frac{\partial Z}{\partial x_{31}}=\frac{\partial f(x)}{\partial x_{31}}-\mathrm{u}_{3}-\mathrm{v}_{1}=-4.78 \\
\frac{\partial Z}{\partial x_{32}}=\frac{\partial f(x)}{\partial x_{32}}-\mathrm{u}_{3}-\mathrm{v}_{2}=4.92 & \frac{\partial Z}{\partial x_{33}}=\frac{\partial f(x)}{\partial x_{33}}-\mathrm{u}_{3}-\mathrm{v}_{3}=9.62
\end{aligned}
$$

The presence of negative values for the reduced cost signifies non optimality; hence we readjust. From the above, the minimum reduced costs for the non-basic variable is $x_{31}$. Therefore $\mathrm{x}_{31}$ should enter the basis since it is the most negative reduced cost. We then move on to next iteration. At the end of this stage of iteration, the basic feasible solution is $\bar{x}^{3}=(7,0,8,0,3,10,0,12,10,0,0,0)$. Next we find the cost equation for the occupy cell. 


$$
\frac{\partial Z}{\partial x_{B i j}}=\frac{\partial f(x)}{\partial x_{B i j}}-\mathrm{u}_{\mathrm{i}}-\mathrm{v}_{\mathrm{j}}=0
$$

Thus,

$$
\begin{array}{rlr}
\frac{\partial f(x)}{\partial x_{B i j}}=\mathrm{u}_{\mathrm{i}}+\mathrm{v}_{\mathrm{j}} & & \\
\mathrm{u}_{1}+\mathrm{v}_{1}=14.4 & \mathrm{u}_{1}+\mathrm{v}_{3}=4 & \mathrm{u}_{2}+\mathrm{v}_{1}=6.9 \\
\mathrm{u}_{2}+\mathrm{v}_{2}=5.2 & \mathrm{u}_{2}+\mathrm{v}_{4}=2.92 & \mathrm{u}_{3}+\mathrm{v}_{1}=1
\end{array}
$$

Letting $\mathrm{u}_{1}=0$, from the equations we have:

$$
\mathrm{u}_{1}=0, \quad \mathrm{u}_{2}=-7.5, \quad \mathrm{u}_{3}=-13.4, \quad \mathrm{v}_{1}=14.4, \mathrm{v}_{2}=12.7, \mathrm{v}_{3}=4, \text { and } \mathrm{v}_{4}=10.42
$$

The net evaluation factor or the reduced costs for the non-basic variables is;

$$
\begin{array}{rlrl}
\frac{\partial Z}{\partial x_{12}} & =\frac{\partial f(x)}{\partial x_{12}}-\mathrm{u}_{1}-\mathrm{v}_{2}=-2.7 & \frac{\partial Z}{\partial x_{23}}=\frac{\partial f(x)}{\partial x_{23}}-\mathrm{u}_{2}-\mathrm{v}_{3}=28.42 \\
\frac{\partial Z}{\partial x_{34}}=\frac{\partial f(x)}{\partial x_{34}}-\mathrm{u}_{3}-\mathrm{v}_{4}=4.78 & \\
\frac{\partial Z}{\partial x_{32}}=\frac{\partial f(x)}{\partial x_{32}}-\mathrm{u}_{3}-\mathrm{v}_{2}=9.7 & \frac{\partial Z}{\partial x_{33}}=\frac{\partial f(x)}{\partial x_{33}}-\mathrm{u}_{3}-\mathrm{v}_{3}=14.4
\end{array}
$$

The presence of negative values for the reduced cost signifies non optimality; hence we readjust. From the above, the minimum reduced costs for the non-basic variable is $\mathrm{x}_{12}$. Therefore $\mathrm{x}_{12}$ should enter the basis since it is the most negative reduced cost. We then move on to next iteration. At the end of this stage of iteration, the basic feasible solution is $\bar{x}^{4}=(0,7,8,0,10,3,0,12,10,0,0,0)$. Next we find the cost equation for the occupy cell.

$$
\frac{\partial Z}{\partial x_{B i j}}=\frac{\partial f(x)}{\partial x_{B i j}}-\mathrm{u}_{\mathrm{i}}-\mathrm{v}_{\mathrm{j}}=0
$$

Thus,

$$
\begin{array}{ccc}
\frac{\partial f(x)}{\partial x_{B i j}}=\mathrm{u}_{\mathrm{i}}+\mathrm{v}_{\mathrm{j}} & \\
\mathrm{u}_{1}+\mathrm{v}_{2}=10 & \mathrm{u}_{1}+\mathrm{v}_{3}=4 & \mathrm{u}_{2}+\mathrm{v}_{1}=6.9 \\
\mathrm{u}_{2}+\mathrm{v}_{2}=5.2 & \mathrm{u}_{2}+\mathrm{v}_{4}=2.92 & \mathrm{u}_{3}+\mathrm{v}_{1}=1
\end{array}
$$

Letting $\mathrm{u}_{1}=0$, from the equations we have;

$$
\mathrm{u}_{1}=0, \quad \mathrm{u}_{2}=-4.8, \quad \mathrm{u}_{3}=-10.7, \quad \mathrm{v}_{1}=11.7, \mathrm{v}_{2}=10, \mathrm{v}_{3}=4, \text { and } \mathrm{v}_{4}=7.09
$$

The net evaluation factor or the reduced costs for the non-basic variables is: 


$$
\begin{array}{rlrl}
\frac{\partial Z}{\partial x_{11}} & =\frac{\partial f(x)}{\partial x_{11}}-\mathrm{u}_{1}-\mathrm{v}_{1}=2.7 & \frac{\partial Z}{\partial x_{14}}=\frac{\partial f(x)}{\partial x_{14}}-\mathrm{u}_{1}-\mathrm{v}_{4}=12.91 \\
\frac{\partial Z}{\partial x_{23}}=\frac{\partial f(x)}{\partial x_{23}}-\mathrm{u}_{2}-\mathrm{v}_{3}=8.32 & \frac{\partial Z}{\partial x_{34}}=\frac{\partial f(x)}{\partial x_{34}}-\mathrm{u}_{3}-\mathrm{v}_{4}=2.5 \\
\frac{\partial Z}{\partial x_{32}}=\frac{\partial f(x)}{\partial x_{32}}-\mathrm{u}_{3}-\mathrm{v}_{2}=9.7 & \frac{\partial Z}{\partial x_{33}}=\frac{\partial f(x)}{\partial x_{33}}-\mathrm{u}_{3}-\mathrm{v}_{3}=11.7
\end{array}
$$

Since all the reduced costs for the non-basic variables are all positive, it implies $\bar{x}^{4}$ is the KKT optimality point. Because optimal solution is our goal, we then proceed to make our allocation and calculate our total optimal cost of transportation.

From our feasible solution, 7000 boxes of P.Red should be supplied to market zone B, 8000 boxes to market zone C, 10000 boxes of Ovidio to market zone A, 3000 to market zone B, 12000 to market zone D, and 10000 boxes of Merlot be supplied to market zone A. Total Cost $=(10 * 7)+(8 * 4)+(10 * 7)+(3 * 6)+(12 * 3)+(10 * 1)$ thousand. Total Cost $=\mathrm{GH} \notin 236,000$.

\section{Conclusion}

We have described the transportation problem of a company as a non-linear transportation problem. We applied KKT optimality algorithm to solve the company's problem. Our research focused on the model of the non-linear transportation problem for a particular company in Ghana. It can however be applied to any situation that can be modelled as such.

This paper aimed at solving transportation problem with volume discount on quantity of goods shipped which is a non-linear transportation problem. Using KKT optimality algorithm, with a data from a Ghanaian company, it was observed that the optimal solution that gave minimum achievable cost of supply was the supply of 7000 boxes of P. Red to market zone B, 8000 boxes to market zone C, 10000 boxes of Ovidio to market zone A, 3000 to market zone B, 12000 to market zone D, and 10000 boxes of Merlot be supplied to market zone A at a cost of $\mathrm{GH} \phi 236,000$.

Using the more scientific transportation problem model for the company's transportation problem gave a better result. Management may benefit from the proposed approach for their transportation problem purposes. We therefore recommend that the transportation problem model should be adopted by the company for their transportation problem planning. 
Our study is limited to a nonlinear transportation problem with concave shape which is as a result of discount given on volume of goods transported. Unlike the linear transportation problems, maximization of profit is realized with discounts on large volumes, which means the determination of the best transportation route that would lead to low transportation cost and the effective transportation of these goods.

\section{References}

Balachandran, V. and Perry, A. (2006) Transportation type problems with quantity discounts. Naval Research Logistics Quarterly, vol. 23, n. 2, pp. 195-209.

Crama, Y., Pascual J, R. and Torres, A. (2004) Optimal procurement decisions in the presence of total quantity discounts and alternative product recipes. European Journal of Operations Research, vol. 159, n. 2, pp. 364-378.

Goossens, D. R., Maas, A. J. T., Spieksman, F. C. R. and de Klundert, J. J. (2007) Exact algorithms for procurement problems under a total quantity discount structure. European Journal of Operational Research, vol. 178, n. 2, pp. 603-626.

Hitchcock, F. L. (1941) The distribution of a product from several sources to numerous localities. Journal of Mathematical and Physics, vol. 20, pp. 224-230.

Ojha, A., Das, B, Mondal, S. and Maiti, M. (2010) A solid transportation problem for an item with fixed charge, vechicle cost and price discounted varying charge using genetic algorithm. Applied Soft Computing, vol. 10, n. 1, pp. 100-110.

Sun, M. (1998) A tabu search heuristic problem for solving the transportation problem with exclusionary side constraints. Journal of Heuristics, vol. 3, pp. 205-326.

Zangwill, W. I. (1967) The convex simplex method. Management Science, vol. 14, n. 3, pp. 221-238. 